\title{
Computing and Social Welfare: Minimizing the Societal Harm From Digital Transfor- mation While Preserving the Benefits of Innovation
}

\author{
Eric K. Clemons \\ The Wharton School \\ clemons@upenn.edu
}

\author{
Ravi Waran \\ Clearwater Paper Corporation \\ Ravi.Waran@clearwaterpaper.com
}

\author{
Victoria Li \\ The Wharton School \\ vli22@sas.upenn.edu
}

\author{
Sebastian Hermes \\ Technical University of Munich \\ Sebastian.Hermes@in.tum.de
}

\author{
Maximillian Schreieck \\ Technical University of Munich \\ Maximillian.Schreick@in.tum.de
}

\begin{abstract}
Social Welfare Computing is an emerging discipline that seeks to direct technology to cause minimum social disruption, and in particular seeks to minimize the harm caused directly by technology. This is markedly different from the better understood strategic use of technology to create value or to address existing social needs. Innovative technologies that are widely adopted created significant value for their users; otherwise they would not be widely adopted. Often the companies that create them obtain new sources of wealth and power, which inevitably lead to new abuses of power and new forms of societal disruption. Societal disruption in turn requires social adaptation, including new regulations to influence the behavior of firms and to define and to protect the rights of an individual in the changed society. Social Welfare Computing seeks to guide social adaptation, combining insights from disciplines as varied as anthropology, business strategy, economics, strategic planning, and law.
\end{abstract}

\section{Introduction}

We are hearing repeated claims that Big Tech has gotten too big and too powerful, and that it needs to be regulated and restrained. We have reviewed several hundred articles describing these claims in order to formulate a comprehensive list of problem areas. These claims are most frequently directed against Facebook, Amazon, Apple, and Google, and the most commonly proposed regulatory fix is the traditional sanction applied to monopolies, breaking the companies up into smaller companies that compete with each other. However, many of the problems that have been created by Big Tech are not caused by the companies' size or monopoly status, and applying antimonopoly sanctions may be both unnecessary and ineffective.

The four largest online companies have enormous power, have transformed traditional consumer services, and have disrupted society in ways we are just beginning to understand. Although the largest tech companies receive the most coverage and the harm they can potentially cause receives the most media attention, we will also address other technology firms, especially in the URI: https://hdl.handle.net/10125/71418

978-0-9981331-4-0

(CC BY-NC-ND 4.0) sharing economy, and explore the unanticipated effects that they have created.

Our research deals with minimizing the harm caused by technology's rapid disruption of society, which is how we have defined Social Welfare Computing $[4,6]$. This has received almost no academic study. Many of our colleagues have studied the benefits and the value created by large scale technological innovation. Others have studied the use of technology to address existing social problems and to improve education and social services. But there has been very little study of the downside of computing, the forms of harm caused by technological progress, and the reduction or mitigation of those problems

\section{Motivation for Our Research Program and Overview of its Structure}

We are conducting a large research program addressing the emerging discipline of social welfare computing $[4,5,6,8,9,10,11,24]$. We acknowledge the extent to which computing both improves aggregate wealth and aggregate social welfare but feel the need to explore the burdens it imposes on some segments of society, perhaps unfairly. Big Tech's power, and the extent of the resulting transformation and disruption, are only possible because of the widespread adoption of technology-driven innovation, and this adoption results from obvious and immediate benefits. Historically, disruption and transformation create losers as well as winners. The speed with which Big Tech firms have emerged is unprecedented. As a society, how should we and when should we act to protect those who are harmed, and who makes the tradeoffs among the value created and the resulting sources of harm?

We avoid expressing our own opinions whenever possible and avoid statements like "big data firms monetize personal information by invading privacy, which is bad." We focus on specific dichotomies, like "big data and private information make markets more efficient, which is good. However, these practices reduce consumer surplus and results in differential pricing, which may be considered unfair, both of which are seen as bad."

Wherever possible, we report the opinions of 
affected segments of society, like parents who may be concerned about privacy and data mining their children's texts, or how users feel about the possibility that Facebook may be complicit in fake news campaigns that seek to manipulate their opinions and may even seek to manipulate the outcome of elections. The opinions have been obtained through interviews, focus groups, and large international surveys.

This is a report on a large ongoing multi-year and multi-disciplinary international research project. It involves studies conducted in the US, in Japan, Korea, and China, in Denmark, France, Germany, and the UK, and in Argentina, Brazil, Chile, Columbia, and Mexico. Work was done with faculty colleagues in all of the first eight countries, involving disciplines like information technology and computer science, information economics and business strategy, law, and anthropology.

Our ultimate goal is to inform public debate and policy discussions, and, ultimately to propose regulation of Big Tech to maximize social welfare, however society and its representatives choose to define social welfare. We are not arguing that Big Tech is good or bad, or that Big Tech firms are or are not too big, or that they do or do not enjoy or abuse monopoly power. We are presenting issues for discussion and moving towards the creation of policy recommendations. In this paper we neither propose nor test hypotheses. However, we believe that the rigor of our analyses and the structure of our research program allows us to avoid proposing a single viewpoint and allows us to guide regulatory policy.

Our research program is a portfolio of interrelated Projects, in six Phases. See figure 1, below, which explains our research plan. It shows how the Projects fit into Phases. The first Phase is Motivation and the Demonstration of the Existence of Problems, which comprises four Projects. This Phase of research is important because it provides the first motivation for our work in assessing the costs and benefits of technological innovation, namely a demonstration that there is a documented history of complaints. The Projects are Recent History of Privacy Litigation, Recent History of Abuse of Power from New Business Models, Recent History of Fake News and Societal Interventions, and Recent History of Complaints about Externalities. The fourth goes beyond our prior publications and involves complaints about sharing economy platforms, such as Airbnb's and Uber's impact on communities. We will elaborate on this in section 6.1 of the paper, where we discuss Phase 4.

The second Phase is Theoretical Background and Historical Precedent, which comprises three Projects. This Phase of research is important because it uses evidence from early millennia of human civilization, and technologies dating back to the agricultural revolution, to demonstrate that technology always alters the structure of society and that these changes always produce winners, losers, and new forms of abuse. When these abuses become sufficiently harmful to social cohesion they produce changes in the implicit and explicit social contracts, and changes in the laws regulating commercial behavior. The three Projects are Technology and Social Structure, Technology and Social Contract, and Technology and the Law. These will not be reviewed in further detail in this paper.

The third Phase is Recent Historical Precedent and Lessons from the Industrial Revolution. The industrial revolution provided the motivation for the first major period of industrial regulation, and this Phase comprises three projects. This Phase of research is important because demonstrates the set of tools available to society and to its regulators for dealing with large technology firms, and prepares us to explore the limitations of these tools for mitigating today's problems in Phase Four. The Projects are Industrial Revolution and Social Structure, Industrial Revolution and the Social Contract, and Industrial Revolution and Regulation.

The fourth Phase is Drawing Lessons from Historical Precedent. This Phase represents more recent research, and the work from this Phase is presented in section 3. This Phase of research is important because demonstrates that the set of available tools is not perfectly designed for mitigating today's problems, and allows us to explore what additional remedies might be appropriate. The four Projects are Monopoly Law and its Limitations, Consumer Safety / Transparency and Labeling Requirements / and their Limitations, Regulation of Externalities and its Limitations, and Regulation of New Business Models and Limitations.

The fifth Phase is Assessment of Current Levels of Support for Regulatory Intervention. This phase comprises four Projects, Interviews with European Executives Exploring American Domination, Consumer Surveys / Trust in Facebook and Google / Trust in Regulators / Willingness to Change, Student and Parental Surveys of Teen Behavior and the Need for Protection, and Surveys of European Executives Exploring American Domination and Need for Regulation. This Phase of research is important because is assesses EU executives' beliefs that they need regulatory protection. It also assesses consumers' satisfaction with current regulation, trust in dominant net platform operators, and willingness to accept further regulation. The two most recently completed projects are summarized in section 7 and represent one of the paper's major contributions beyond our previously published research.

The sixth and final Phase is Policy Recommendations, which comprises a single Project, Implications for Policy and Regulatory Recommendations. This Phase can't be completed until we complete all prior Phases. When completed, this Phase of research will be the most important contribution of our entire research program. Preliminary findings are presented in section 8 . 


\section{Problems Created by the Internet / Digital Revolution for Which Regula- tors Have Solutions}

\subsection{Economies of Scale as a Source of Power in Online Platforms}

Virtually all software exhibits extreme economies of scale. Development costs are high, as in many forms of innovation, but with digital downloads the cost of producing and selling additional copies has dropped to zero. Virtually all software, like MS Windows and MS Office, enjoys enormous competitive advantage in part because its average per-copy cost, as well its marginal cost, are lower than any smaller competitor could match. Google Search also enjoys advantage because the larger its user base the faster its search results adapt to changing conditions in the external world.

\subsection{Traditional Network Effects}

Communications networks, from traditional telephony to social media networks like Facebook and Twitter, gain their value in large measure from the number of users they have. The value increases faster than the number of network users. With limited interconnectivity and dedicated hardware, early networks emerged as natural monopolies. Today, limited interconnectivity is often artificially imposed as a means of achieving monopoly power or extending it into new domains [3].

\subsection{Economies of Scope and Positive Exter- nalities on the Supply Side}

Users gain value from increasing the number of participants on the other side of the market. When Microsoft's DOS became the most widely used operating system other than Apple's it attracted more software developers, which attracted more users, eventually reaching a tipping point and virtually eliminating its competitors. Numerous other examples have been studied [23].

\section{Problems Created by the Internet / Digital Revolution for Which Regula- tors Do Not Have Solutions \\ 4.1.The Externality Problems Caused by Online Platforms}

Modern software platforms have impacts beyond their users, and these are very different from traditional externalities like congestion or pollution. Negative externalities occur when users of a product or service gain value themselves, but cause harm to others. Markets rarely solve problems with externalities because the individuals who cause harm do not suffer harm themselves, and may even be unaware of the harm they cause. Users love Uber because of its convenience, speed, and low cost, but may increase urban pollution and traffic congestion by shifting users away from more efficient mass transit. Airbnb provides users the ability to live in historical neighborhoods on vacation but this displaces long-term residents, who have come to despise Airbnb.

\subsection{Platform Envelopment}

A platform is a core system that can readily be extended. Platform envelopment involves the combination of the following three characteristics: (1) Monopoly control over the core system, (2) Super-additive value creation as each additional application added to the core creates more value for users, including increasing the value of the core and some or all of the applications already added, and (3) the ability to deliberately reduce access to the core or to deny access to the core entirely, to cripple potential competitors [3].

Platform envelopment strategies have existed for decades. The Radio Commission, the precursor of the Federal Communications Commission, was created to address the first occurrence of platform envelopment, when AT\&T leveraged its control over long distance telephony to create a monopoly in radio networks [3].

Platform envelopment has become much more prevalent with the increased importance of software platforms [6]. The best known examples involve Microsoft $[3,8]$ and Google $[3,29]$.

It is easy to view platform envelopment as an opportunity for all businesses to develop their own platform strategies [21]. This is probably dangerously misguided. Dominant platforms are already well-established. Android is already free both to users and to hardware vendors, and it enjoys enormous network benefits from millions of apps available.

There are few remedies available. The Essential Facilities Doctrine would limit the abuse of platforms like Android. It might be argued that Android is now an essential facility for app developers who wish to sell to users of non-Apple devices. Duty to Deal argues that a firm cannot refuse to work with a competitor it has worked with previously, solely for commercial reasons [13]. Neither of these is universally accepted legal doctrine, and the EU is currently treating platform envelopment as a novel abuse of monopoly power.

\subsection{Deceptive, Dangerous, and Addictive Social Media Products}

Facebook's role in the crafting and dissemination of fake news has been widely reported [30, 20]. Facebook's role in radicalization and recruiting for extremist organizations has been widely reported [1]. Facebook played a role spreading rumors during periods of unrest and dangerous medical misinformation, as they are doing during the current pandemic.

Search can be dangerously and deliberately inaccurate, as with Google's support of illegal smuggling of counterfeit pharmaceuticals through dummy websites 
established to look as if they were Canadian [28].

Users are enticed to use more and more applications on a single platform, and the more they use, the more the platform learns about them. The more that platform learns about them the better the platform's services become. The dark side of this capture and integration of information is better manipulation of the users, better targeted marketing, and better precision pricing. As firms learn to price products and services to match each individual's willingness to pay markets do become more efficient, but consumer surplus is also reduced; that is, more and more of the value of technology is appropriated by the provider, not by the user.

The easiest approach to limiting the harm from deceptive, harmful, and addictive products would be labeling, and this would work if users care enough to act differently if they did know. However, there is evidence that by itself labeling to increase transparency may not be effective. This has been observed in products as diverse as cigarettes and fake news [25].

Freedom of speech makes it difficult to prohibit all but the most abusive material. Moreover, Facebook argues that its use of personal information to target fake news to the most responsive readers is part of its core strategy of ensuring that users see the content that is most interesting to them, which is protected even within the EU's GDPR.

One recommendation is to regulate social networking platforms as harmful and addictive products, much as we regulate tobacco and alcohol, as suggested by Professor Jan Trzaskowski of Copenhagen Business School. Alternatively, they could be regulated as unsafe public spaces, as suggested by Professor Amanda Shanor of The Wharton School.

\subsection{New Problems - Gateways and Third Party Payer Systems}

Google and Amazon control critical online gateways. Amazon, and its Alexa, and Google, and its online assistant, are becoming dominant forces in postpandemic retailing, with power and reach well beyond that of any traditional retailers.

Perhaps the most interesting business model of the internet is the combination of an online gateway with a third-party payer system. Google is essential for users who want to find sellers, and sellers know this; hence sellers are willing to pay to be found, and willing to pay to avoid being hidden from buyers. Over time search platforms have become essential, and have mastered the art of charging sellers to be found, and of transferring part of the payments they receive to buyers to maintain their loyalty. When search engines compete they actually increase rather than decrease the prices they charge sellers to be found and then increase the payment to users to buy more loyalty. These mandatory participation third party payer systems are perhaps unique; they appear to be the only businesses where competition causes the competitors to increase the prices they charge their customers, and then use the revenues to buy loyalty. These reverse price wars are successful because party1 , the users, do not know about or care about the prices charged to party-3, the sellers, and because party- 3 has no choice. If users use only one search platform, which is true of most users, then party- 3 has to participate in all platforms, and cannot reject a platform simply because it has become more expensive. There may not be a market solution that can eliminate reverse price wars. These are still a serious problem today, four decades after the first legal judgments against them [3].

Precision pricing and abuse of the most needy and least informed has been discussed briefly as one of the dangers of harmful and addictive platform usage. Fully informed sellers can exploit perfect information, can perform perfect price discrimination, and can extract an increasing fraction of the value created by innovation [31]. This is efficient pricing, and marketers and economists have dreamed of it for years. Is efficient pricing always appropriate? As a society, do we agree? And if not, how do we prohibit it? There is no market solution. Companies that can attract and retain the most profitable customers always outperform their competitors [3].

We are experiencing unprecedented concentration of economic and political power without necessary regulatory checks. No company in history has ever grown to $\$ 250$ billion as quickly as Facebook, and no company has ever grown ubiquitous as quickly as Facebook. Facebook is global and there are no checks or restrictions that prohibit its being used to encourage genocide in Myanmar, or to recruit for the Islamic state, or to support dictatorship in the Philippines [1].

Do we have consensus on our right to regulate Big Tech or on what forms of regulation are appropriate? Would the firms even permit regulation? Or have they become so powerful, so able to manipulate legislators through lobbying, and so able to manipulate consumers' views that they are now beyond regulation?

\subsection{New Problems - Emergence of Power- ful Life Control Interfaces}

Smartphones and at-home digital assistants have become far more than phones, and indeed far more than devices for communicating with other people. They have become our life control interfaces [24]. They contain our schedules, our plans, our to-do-lists, our contacts, our photographs. They are our indispensable cybernetically enhanced memories. They are our access points to the net, including our access to search and to shopping, and to services ranging from restaurant delivery to taxis and other forms of local transportation. We use them to manage our schedules, order our groceries, control our music and our television and even the 
lighting in our homes. They provide real-time directions, and even when we do not let them actually control our movements we let them influence or decide our movements for us.

Life control interfaces influence, and even determine, what we buy and where and when we buy it. As the emerging internet of things enhances the power of smart appliances and autonomous vehicles, life control interfaces will become increasingly important, and their American owners will gain dangerous power over the behavior of all European consumers.

Platforms are increasingly not neutral agents that we control. Increasingly, these life control interfaces have their own agendas, and subtly control our lives while we believe we are controlling ourselves [31. If we ask Alexa to get us six cans of lentil soup, we know where she is going to shop. She will direct the order to one of Amazon's own operations, but at least she will probably order our favorite brand. If we ask Google to get us the same thing, both the brand and the price are certain to be acceptable, but both the brand and the store will be determined by algorithms like those used for sponsored search. With Alexa many retailers are squeezed out of the distribution channel, and with Google retailers and manufacturers once again are forced to pay to participate.

Consumers are not harmed in any obviously way, and will increasingly become dependent upon their life control interfaces. But competition is harmed, and retailers will increasingly be harmed by this new form of anticompetitive behavior. Likewise, consumers will not be able to obtain the full range of value from their smart cars without a relationship between the car manufacturer and the owner of the interface, Android or iOS. Likewise, manufacturers will not be able to achieve the full range of value from their smart home appliances without a relationship between the car manufacturer and the owner of the interface, Android or iOS.

\section{Why is it so Hard to Develop Appropri- ate Responses to the Power of Big Tech?}

It has been extremely difficult to develop a strategy for responding to the power of Big Tech companies. We cannot agree on the questions to ask. We cannot agree on what regulation should look like or on what social policy should look like until we agree on what problems we are facing and how we would know when we found an appropriate solution.

It's impossible to implement any solution without consensus on what the problem actually is. It's impossible to implement any solution without an understanding of individuals' objectives and without understanding the tradeoffs among them. Without this understanding we would lack public support for any proposed solution. That's why we have conducted extensive survey research, in order to understand consumer behavior.
This is described in detail in section 7.

Similarly, we will need to understand the concerns of executives in industries directly affected by the power of Big Tech, its power over existing gateways to control access to consumers, and the emerging power of life control interfaces like Alexa.

And we will need to understand how to teach people to make decisions in their own long-term best interest, which includes understanding motivation and selfcontrol, and both analytical and intuitive decision-making. This is described in detail in section 7.

This is why we are arguing so insistently for interdisciplinary research. The relevant disciplines obviously include information economics and business strategy, to understand what Big Tech firms want to do, and how different regulatory restraints would affect their ability to act in ways that regulators deem undesirable. They would also include regulatory policy and regulatory economics. We will also need to include anthropology, sociology, and consumer psychology, so that we know what consumers do and do not already understand, what consumers do and do not want, and what consumers will and will not accept both from their services providers and from their governments. Without this it will be impossible to design a regulatory policy that consumers will accept. There are lessons that must be learned from Big Tech's ability to derail both the US Congress and the US Senate's attempts to limit online theft and republication of protected content.

\section{What Responses are Appropriate to the Problems of Digital Transformation of Business and Society?}

The most common recommendation in response to Big Tech is to apply antimonopoly law more strictly [17]. Historically, many problems have not been solvable through antimonopoly law. The harm from tobacco addiction was not caused by the monopoly power of any individual tobacco company, but by lack of transparency regarding harm, by powerful advertising and lobbying efforts, and by humans' well-known inability to trade off immediate benefits against long-term harm. The solution was a combination of mandatory labeling, increased taxes, and outright ban on sale to minors. The problem of lead in gasoline was not caused by the monopoly power of gasoline companies around the world, but again by lobbying and lack of transparency concerning future harm. The problem was solved by actions banning leaded gasoline in the entire industrialized world and by requiring automobile companies to produce vehicles that did not require leaded gasoline. The problems of externalities - harm to others caused by our own economic activities - are not caused by monopolies. The most obvious examples, such as air and water pollution, are not caused because coal companies, other extractive industries companies, refineries, and 
chemical companies are monopolies. They are caused by a lack of transparency: we cannot immediately judge the harm we are causing others. And they are caused by a lack of altruism: we don't care about the harm our activities cause others. The problems of defective, harmful, or addictive products were not caused by monopoly power.

Additionally, some of the problems we face today are without precedent. The power of platform envelopment is not caused directly by the existence of a monopoly, but by the leverage of that monopoly to create additional power in other areas of economic activity.

\subsection{What Solutions are Appropriate for Ex- ternalities?}

Uber increases traffic congestion and increases air pollution by reducing reliance on more fuel-efficient public transportation. Airbnb alters neighborhoods, allowing residential housing to be converted to commercial near-hotels and forcing out long-time residents. And yet city-dwellers love Uber, and tourists and many parts of the tourism industry love Airbnb.

There is no universal solution. Solutions need to be negotiated locally among all stakeholders. But who should be consulted? Should hotels be represented, since they are harmed? How can foreign tourists be represented in local analysis of tradeoffs?

\subsection{What Solutions are Appropriate for Platform Envelopment?}

There has been little academic study of the problems of platform envelopment, although regulators are beginning to act. The Department of Justice litigation against Microsoft was at its core about platform envelopment. The record-setting $€ 4.34$ billion judgment of the EU Competition Commission against Google was likewise about platform envelopment and about denying competitors equal access to their Android platform.

Since platform envelopment revolves around denying access to an essential platform, an effective solution would require allowing unrestricted access. This requires that a firm provides services to its competitors. Duty to deal in the US is usually applied only when a company that had been providing services ceases to do so solely for anticompetitive reasons [14]. Likewise, although the Essential Facilities Doctrine [22] was effectively used in litigation against American Airlines' abuse of Sabre and to compel AT\&T to provide MCI access to individual subscribers' phones, it is now seldom employed either in American or EU litigation. Analysis is complicated in part because consumers do benefit from the super-additive value created by the platform operator [3]. The key decision is determining a fair price that the platform owners charge for access.

\subsection{What is the Appropriate Remedy for Abuse of Control of Gateways?}

Abuse of gateways is a dominant online business model, especially when combined with third party payer systems and reverse price wars. Consumers rarely see the indirect costs they create for themselves by using free search. Search engines are not required to provide consumers with the best possible search results, and sometimes, when the profits are large enough, they will return search results that are actually dangerous and harmful. The most extreme examples involved Google's facilitating illegal drug smuggling into the United States [27].

But harmful search results are rare today. Google has learned that allowing inferior suppliers to purchase top spots in search is rarely good business. Consumers would learn to distrust paid search results, which would be catastrophic for Google's business model. And it is more profitable to provide the top spots in sponsored search to suppliers that consumers will actually click on, since that produces revenue. Google uses a combination of the seller's quality score and the seller's bid to determine its location in the search results it shows users. Google reserves the right to adjust quality scores in order to extract as much money as it chooses to extract from winning bidders, but it rarely shows truly inferior sellers to consumers any more. It uses the threat of not showing a particular seller as a mechanism for extracting high prices even from sellers who should automatically show up at the top of search.

Some of the profits extracted by the search engine are returned directly to consumers through a range of other services, making search engines appear to be more free than free. These payments are used to buy loyalty from users and to increase market share. As a result, competition among search engines actually increases the price they charge sellers to be found. Breaking up Google would not reduce the cost of keywords, or the costs sellers pay as a result of participating in search, but would actually increase them. Since a significant portion of higher costs are always passed along to consumers, free search may ultimately prove to be the most expensive way of providing search. Since breaking up Google would only increase the cost of keywords, and thus would only increase the indirect costs of free search paid by consumers, we need another mechanism. Both the cost of keywords and preferencing of a search engine's own offerings above those of competitors have led to the imposition of massive fines by the EU's Competition Commissioner.

Bracha and Pasquale have suggested the creation of a Federal Search Commission [2]. Their intent was to eliminate search bias and ensure that consumers obtain the best possible search results. But the FSC could also address two other problems created by the current 
market for search. It could set tariffs and limit the costs imposed by any search. It could eliminate abuses such as preferencing the search engine's own offerings ahead of those of other competitors.

Regulation of search will not be easy. Our most recent research suggests that even in 2020 consumers do not approve of Google's behavior but would be reluctant to share data with any Google competitor and would be reluctant to switch to a paid service even if it preserved their privacy $[6,15]$.

\subsection{What Solutions are Appropriate for Re- stricting the Use of Social Media for Ma- nipulation?}

Social media are used to manipulate public opinion, both in elections and in marketing. Social media are used to advocate extremist political or religious ideas, and to radicalize and recruit new members for a wide range of dangerous extremist groups. The problem has been called an existential threat to democracy [20], but Facebook has successfully defended its practices using arguments related to freedom of speech and to its use of data to as part of its core marketing strategy.

Jaron Lanier has suggested that we all terminate our accounts and stop our use of social media [14], but Jaron's readers are not among Facebook's most susceptible users. Mark Zuckerberg expressed no concern about a boycott by advertisers, since he was certain that they would all come back.

\subsection{What Solutions are Appropriate for Abuse of Life Control Interfaces?}

Life control interfaces require data to operate, and these are cospecialized assets in the sense described by Teece [27]; firms that control cospecialized assets are the firms that profit from innovations. Clemons and Row explain how this is especially true in informationbased innovations [7]. A smart car needs data in the user's phone to arrange to pick up guests and drive them to dinner, a smart shopping assistant needs access to other information stored elsewhere in the user's life control interface. No single automobile manufacturer, appliance manufacturer, or retailer can provide a compelling reason for users to reenter their data or for them to adopt a new life control interface. Apple iOS, Google Assistant, and Amazon are here to stay.

The most plausible response would be the creation of a single cooperative pan-EU life control interface that is transparent, regulated, and agnostic about where to shop and would have full access to the consumers' data. The GDPR ensures that users own their data and that they have the right to download data to any competing platforms, but most users lack the patience, the skill, and the motivation to do so. A pan-EU life control interface could provide motivation, by offering superior unbiased service, and could provide access to the data necessary for the interface's operation.

Alternatively, Alexa, Android, and iOS could be regulated as essential facilities in the US, the model for regulating airline reservations systems in the 1980s.

\section{Support For Regulatory Actions}

We explored the level of support among consumers and among executives for increased levels of regulatory protection. We believe that this is essential because it provides motivation for regulators as well as insights into how proposed regulation will be received and which forms of regulation will be effective.

\subsection{Completed Work - Online Behavior of Young Users and Parental Concerns}

Not surprisingly students engage in unsafe behavior online, and not surprisingly there is parental support for increased protection against data mining their children's online behavior. This was true in all 12 countries in which we conducted surveys $[8,10,11]$.

\subsection{Recent Work - EU Executives' In- creasing Understanding and Increasing Levels of Concern}

We examined the attitudes of EU executives towards American domination of the net and their domination of customer-facing online interactions [6, 15]. Executives exhibited a range of concerns and a range of explanations for this domination. We used ethnographic observation and the tools of anthropology to guide our work exploring executives' own concerns.

We sought to assess whether executives saw this domination as a problem for European firms. Executives discussed the following issues: (1) Concerns rooted in fear of monopoly power regardless of nationalities of the owners, (2) Concerns because a small number of firms controlled critical infrastructure, (3) Concerns because the dominant firms are American and not European, (4) Concerns because these firms were not subject to European standards of regulation and did not adhere to European codes of behavior, or (5) no problem at all as long as there was sufficient competition among dominant firms.

We meet with senior executives from 17 firms in Germany, 6 in Denmark and 5 in France and with one European regulatory institution. We spoke to individuals from 14 different industries. The interviews explored enough points of view, from enough industrial sectors, to capture the most important questions.

The following emerged as executives' beliefs about the sources of initial American domination:

- Greater risk tolerance of American finance, more fear of missing out on the next Google than fear of investing in another Pets.com 
- American firm's greater willingness to risk potentially illegal behavior during periods of regulatory ambiguity

- Privacy policies that allowed American firms huge income streams from privacy mining, not available to EU firms

- Lack of enforcement of antimonopoly law, allowing creation of platform monopolies like Android, funded in part from privacy mining

- Competing in a single market with a single language and a common culture

- Competing in a market that had always been more open to early adoption of technology

The following emerged as executives' explanations for sustained American domination:

- Continued American privacy mining as a source of revenue not available to EU firms

- Cross-subsidies and funding of additional ventures out of these revenues, and the creation of new sources of American monopoly power

- Platform envelopment and the use of American platforms like Android and gateways like Alexa to create new sources of monopoly power

There is a greater level of concern among EU executives than we observed previously. There is still a lack of consensus on the source of American domination. There is also a lack of consensus on how to respond and if an effective response is available in the absence of regulatory interventions. When executives did believe that intervention was possible, they focused on ending American firms' ability to use revenues from privacy mining to subsidize new sources of monopoly power, and on ending platform envelopment and leveraging platforms like Android to exclude competitors.

\subsection{Recent Work - EU Consumers' Level of Concern with Google and Facebook}

We conducted surveys to examine consumers' attitudes towards new business models and towards firms that monetize consumers' personal information. Surveys assessed consumers' knowledge of Google's and Facebook's current business practices and also assessed their approval or disapproval of those practices, independent of their belief that those practices currently occurred $[15,16]$. This allowed us to determine implicit informed consent; individuals who both knew of and approved of these practices. We also studied their willingness to switch to alternative clean services, that is, services that do not violate privacy or monetize private information. We studied their degree of satisfaction with regulatory current levels of regulatory protections. We saw very little differences among consumers in France, Germany, the UK, and the US. When compared to our own previous studies, we saw a slight increase in informed consent; this was not due to an increase in consumers who approved of Google's practices of Google and Facebook, and is explained by a slight increase in consumers who were now aware of Google's practices. Our study contributes to the design of regulatory policies to improve consumer welfare by assessing consumers awareness, willingness to take actions to protect themselves, and levels of satisfaction with existing regulatory protections.

Consumers' levels of informed consent were quite low, averaging $5 \%$, and only once reaching $10 \%$ (consumers awareness that Google used GPS positioning in making recommendations). Consumers in general were not satisfied with the levels of protection they received from their regulators' ability to ensure they were aware of company practices, aware of potential for harm, and actually protected from harm. Percentages satisfied for each question for Facebook were $(22.0 \%, 21.6 \%$, and $21.2 \%)$ and for Google were $(23.2 \%, 24.6 \%$, and $24.5 \%)$.

However, it is difficult to determine if consumers are likely to protect themselves or to approve of regulatory actions to protect them. While consumers do express a preference for safer alternatives, and expressed a willingness to switch to them if they were available (Facebook, $41.2 \%$, Google $41.5 \%$ ), very few were willing to pay for safer services $(31.5 \%, 30.6 \%)$. Regulatory action to protect consumers' privacy would invariably result in higher prices for services, and the value that consumers currently place on their privacy appears to be quite low. Consumers might be willing to accept costs of using newer cleaner services if they were more aware of the real but hidden costs of using Facebook and Google; that suggests that regulators will find consumers more accepting if regulation is accompanied by actions that increase transparency and consumer awareness of how they are actually being harmed. Alternatively, the privacy paradox might be quite real, and while consumers claim to want more protection they are truly unwilling to pay for it. That would suggest very limited acceptance of enhanced protection, even protection that limits uses of data that consumers find dangerous or damaging. It would also suggest that increased public awareness of abuses by large online platforms would not result immediately in reduced usage.

\section{Other Considerations}

Technology and online applications do not respect any international borders. Any attempt to regulate Western firms must be approached carefully, or we will cripple our domestic firms and create opportunities for them to be replaced by new entrants with worse behavior.

Regulation is only one approach. Market solutions would work if the public's commercial behavior considered the impacts to others and avoided harmful externalities. Unfortunately, the lack of transparency ensures that the public is mostly unaware of the harm that Big Tech causes. And there is little indication that diffuse 
harm changes individual behavior. Higher prices that result from merchants' key word costs seems an abstract and theoretical danger, and the joys of staying in a perfectly located Airbnb dominate concerns for displaced local residents. Can we implement policy without public support? Should we? Do we have the right to do so?

Other authors have suggested that the moral education of the firm, its executives, and its board of directors, would lead to a new social contract between firms and society. Employees, customers, and society as a whole would be included among the firm's stakeholders, and would reduce the role of shareholders, profits, and market valuation as metrics of a firm's performance [26].

\section{Conclusions 9.1.Contributions}

We have focused on some of the most pressing problems facing modern society. We addressed a small set of problems that are novel, or newly significant, and that are not yet resolved by current regulation. Moreover, we have explained why these are problems that are unlikely to be solved by transparency, by changes in consumer behavior, by market forces, or even by a combination of all three. These problems require interdisciplinary study. And we have sketched out how some of these problems might be approached.

\subsection{Limitations and Suggestions for Future Research}

This work is preliminary. It addresses work in five of our six phases, but stops short of making policy recommendations. It is both a summary of completed work and a call for further interdisciplinary research.

Steps forward are based on continued cooperation with a diverse set of colleagues globally. We will continue to seek input from executives, consumers, and the platform operators themselves. We will continue to work with regulators, principally in Europe, and wherever they appear open to academic suggestions.

\section{References:}

[1] Maeghin Alarid, "Recruitment and Radicalization: The Role of Social Media and New Technology", 2016, https://cco.ndu.edu/News/Article/780274/chapter-13-recruitment-and-radicalization-the-role-of-social-mediaand-new-tech/.

[2] Oren Bracha and Frank Pasquale, "Federal Search Commission? Access, Fairness and Accountability in the Law of Search", 2008, https://www.lawschool.cornell.edu/research/cornell-law-review/upload/BrachaPasquale-Final.pdf.

[3] Eric K. Clemons, New Patterns of Power and Profit: A Strategist's Guide to Competitive Advantage in the Age of Digital Transformation, 2018, Switzerland: Palgrave Macmillan.

[4] Eric K. Clemons, Markus Böhm, Andreas Hein, Sebastian Hermes, Jörg Weking, and Helmut Krcmar, "New
Business Models Require New MIS Research Paradigms: Information, Societal Disruption, The Future of Work, The Future of Democracy, and The Future of Capitalism”, 53rd International Conference on System Sciences, Maui, Hawaii, January 2020.

[5] Eric K. Clemons, Rajiv M. Dewan, Robert J. Kauffman, and Thomas A. Weber, "Understanding the Information-Based Transformation of Strategy and Society", Journal of Management Information Systems, Vol. 34 No. 22017 pp. 425-456.

[6] Eric K. Clemons, Helmut Krcmar, Sebastian Hermes, and Jeena Cho, "American Domination of the Net: A Preliminary Ethnographic Exploration of Causes, Economic Implications for Europe, and Future Prospects, Proceedings, 52nd International Conference on System Sciences, Maui, Hawaii, January 2019.

[7] Eric K. Clemons and Michael C. Row, MIS Quarterly Vol. 15, No. 3, Special Issue: [Strategic Use of Information Systems] (Sep. 1991), pp. 275-292.

[8] Eric K. Clemons and Josh Wilson, "Families Decisions Regarding Online Privacy and Targeted Ads, And Regulatory Implications", Journal of Management Information Systems, Vol. 32 No, 22015 pp. 40-70.

[9] Eric K. Clemons and Josh Wilson, "The Future of Academic Research in Information Systems Economics: From Information Systems and Strategy to Innovative Business Models, Social Impacts, Public Policy, Regulation, and the Law", Proceedings, 51st International Conference on System Sciences, Waikoloa, Hawaii, January 2018.

[10] Eric. K. Clemons, Josh Wilson, Fujie JIN, “Students' and Parents' Attitudes towards Online Privacy: An International Study", Proceedings, 48th Hawaii International Conference on System Sciences, Wailea, Hawaii, January 2015.

[11] Eric. K. Clemons, Josh Wilson, Fujie JIN, "Investigations into Consumers Preferences Concerning Privacy: An Initial Step Towards the Development of Modern and Consistent Privacy Protections Around the Globe", Proceedings, 47th International Conference on System Sciences, Wailea, Hawaii, January 2014).

[12] Thomas R. Eisenmann, Geoffrey Parker and Marshall Van Alstyne, 2011, "Platform envelopment", Strategic Management journal, 32(12), 1270-1285.

[13] Federal Trade Commission, "Refusal to Deal", Retrieved 12 July 2020, https://www.ftc.gov/tips-advice/competition-guidance/guide-antitrust-laws/singlefirm-conduct/refusal-deal.

[14] Findlaw, “ASPEN SKIING CO. V. ASPEN HIGHLANDS SKIING CORP.', 1985, https://caselaw.findlaw.com/us-supremecourt/472/585.html.

[15] Sebastian Hermes, Eric Clemons, Maximilian Schreieck, Simon Pfab, Maya Mitre, Markus Böhm, Manuel Wiesche, and Helmut Krcmar, "Breeding Grounds of Digital Platforms: Exploring the Sources of American Platform Domination, China's Platform Self-Sufficiency, and Europe's Platform Gap", 28th European Conference on Information Systems, Marrakesh, Morocco.

[16] Sebastian Hermes, Eric K. Clemons, David Wittenzellner, Andreas Hein, Markus Böhm and Helmut Krcmar (2020), Consumer Attitudes towards Firms that Mone- 
tize Personal Information: A Cluster Analysis and Regu-latory Implications, Paper presented at the 24th Pacific Asia Conference on In-formation Systems, Dubai, Unit-ed Arab Emirates.

[17] Brent Kendall and John D. McKinnon, "Justice Department, State Attorneys General Likely to Bring Antitrust Lawsuits Against Google", 2020, https://www.wsj.com/articles/justice-department-stateattorneys-general-likely-to-bring-antitrust-lawsuitsagainst-google-11589573622.

[18] Daniel Knight, "The Rise of the Microsoft Monopoly", 2008, https://lowendmac.com/2008/rise-of-microsoftmonopoly/.

[19] Jaron Lanier, Ten Arguments For Deleting Your Social Media Accounts Right Now, 2018, Henry Holt and Co.

[20] John Naughton, "Social media is an existential threat to our idea of democracy", The Guardian, Dec. 23, 2018, https://www.theguardian.com/commentisfree/2018/dec/23/social-media-existential-threat-ideademocracy.

[21] Geoffrey G. Parker, Marshall W. Van Alstyne and Sangeet Paul Choudary, Platform Revolution: How Networked Markets Are Transforming the Economy-and How to Make Them Work for You, 2016, W. W. Norton Company.

[22] Robert Pitofsky, Donna Patterson and Jonathan Hooks, "The Essential Facilities Doctrine Under United States Antitrust Law", 2010, https://scholarship.law.georgetown.edu/cgi/viewcontent.cgi?article $=1342 \&$ context $=$ facpub.

[23] Jean-Charles Rochet and Jean Tirole, "Two-Sided Markets: An Overview", 2004,

https://web.mit.edu/14.271/www/rochet_tirole.pdf.

[24] Maximillian Schreieck, Eric K. Clemons, Manuel Wiesche and Helmut Krcmar, "Competing with Giant
Platform Operators: An Analysis of Which Traditional Manufacturing Companies are at Risk from Strategic Dependence on Other Companies' Platforms in the Emerging Era of the Internet of Things", 2019, http:/questromworld.bu.edu/platformstrategy/files/2019/07/PlatStrat2019 paper 48.pdf.

[25] Jason Schwartz, "Tagging fake news on Facebook doesn't work, study says", 2017, https://www.politico.com/story/2017/09/11/facebook-fake-news-factchecks-242567.

[26] Andrew R. Sorkin, "How Shareholder Democracy Failed the People", 2019, https://www.nytimes.com/2019/08/20/business/dealbook/businessroundtable-corporate-responsibility.html?ac-

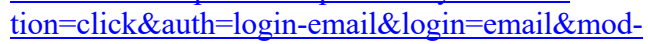
ule=RelatedLinks\&pgtype $=$ Article .

[27] David J. Teece, "Profiting from technological innovation: Implications for integration, collaboration, licensing and public policy", 1986.

[28] United States Department of Justice, "Google Forfeits $\$ 500$ Million Generated by Online Ads \& Prescription Drug Sales by Canadian Online Pharmacies", 2011, https://www.justice.gov/opa/pr/google-forfeits-500million-generated-online-ads-prescription-drug-salescanadian-online.

[29] Gian Volpicelli, "Margrethe Vestager fined Google and Apple billions, now she may lead Europe", 2019, https://www.wired.co.uk/article/margrethe-vestagereu-fines-google.

[30] Christopher Wylie, Mindf*Ck: Cambridge Analytica and the Plot to Break America, 2019, Random House.

[31] Shoshana Zuboff, "You Are Now Remotely Controlled", 2020, https://www.nytimes.com/2020/01/24/opinion/sunday/surveillancecapitalism.html.
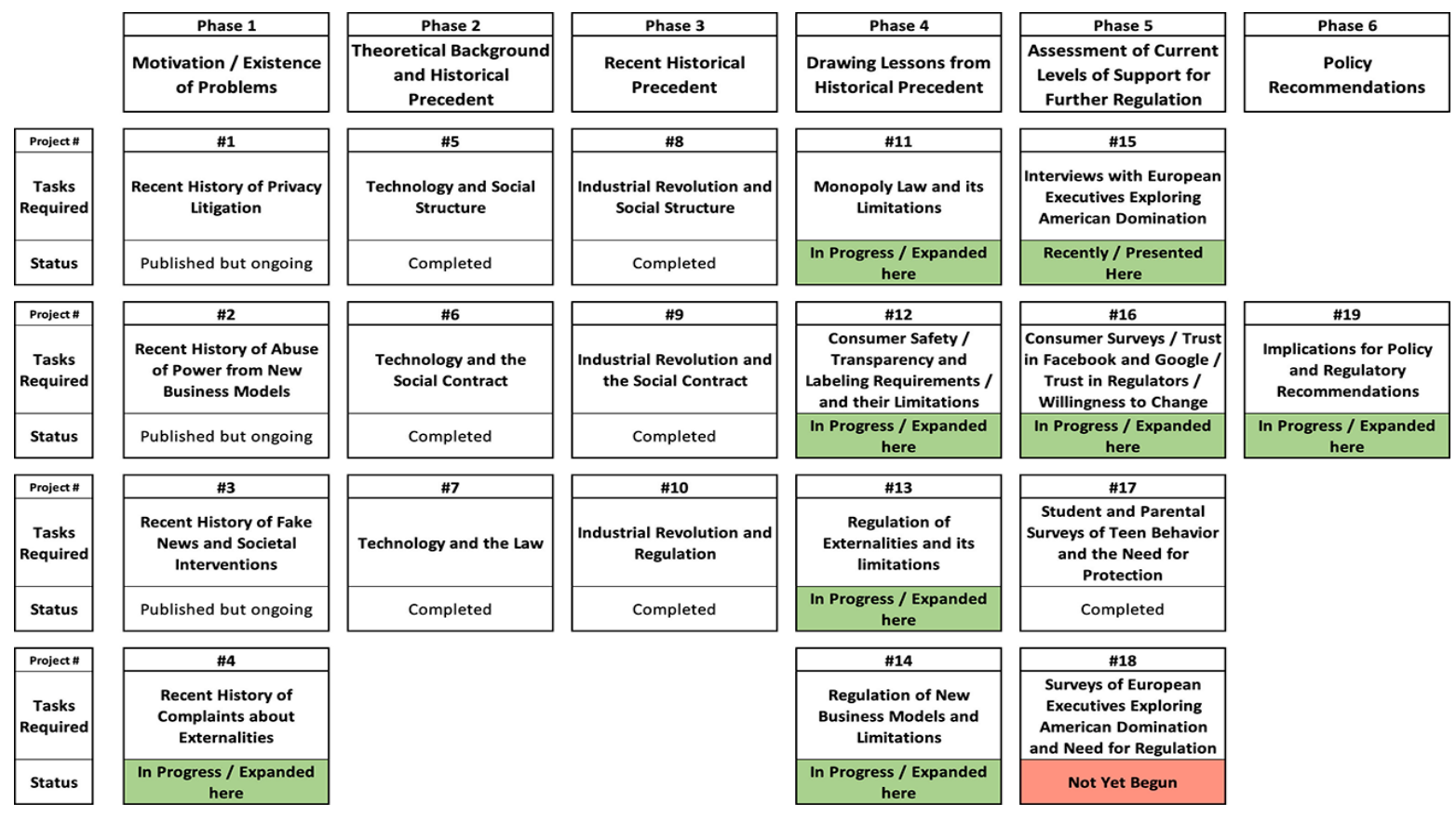

Figure 1.- Structure of the Research Program, Detailing Phases, Projects within Phases, Status, and Key Findings Published to Date. 